\section{Data sharing: guard the privacy of donors}

I endorse Emma Kowal and colleagues' call for moreresponsible sharing of people's research data (Nature 546, $474 ; 2017)$. The reuse of data without participants' consent is a serious ethical problem and could discourage participation in future projects (see, for example, go.nature.com/2ub6qrq).

To the chagrin of privacy advocates, the US Department of Health and Human Services introduced reforms in January that allow sharing of medicalresearch data without re-consent by patients (see Nature 541, 449; 2017). Researchers must now share their archived data, which were collected before the National Institutes of Health (NIH) data-sharing policy of 2003 and when consent forms did not let people opt out of having their data shared. Researchers who fail to comply can have their NIH funding withheld (see go.nature.com/2vzjthi).

This policy is particularly problematic for anonymous donors who have stigmatizing conditions such as alcohol or drug addiction. De-identified data in family collections can now be identified using genealogy databases (J. Bohannon Science 339, 262; 2013). With the hacking of medical records for profit becoming more pervasive in the United States (see go.nature. com/2uytcpg), people who donated their private information could now be compromised. Shirley Y. Hill University of Pittsburgh School of Medicine, Pittsburgh, Pennsylvania, USA. syh50@pitt.edu

\section{Data sharing: do scientists know best?}

Emma Kowal and colleagues argue against restricting access to genomic data collected from indigenous peoples (Nature 546, $474 ; 2017$ ), citing our study of Aboriginal Australians as a case in point (A.-S. Malaspinas et al. Nature 538, 207-214; 2016). In fact, the collection of these samples was fully in accordance with Australia's National Statement on Ethical Conduct in Human Research. Moreover, the researchers worked with the Aboriginal donors to develop the conditions for data sharing.

Kowal et al. mischaracterize this ethical framework as a perceived series of "hurdles" in the pursuit of scientific goals. Also, many researchers hold the view that journals have a moral obligation to make genomic data publicly available, when journals' only responsibility is to ensure that the work was ethically conducted and that the findings are reproducible.

In our view, the implication that scientific goals should take priority over the rights and concerns of indigenous participants smacks of a paternalism that has dogged this research field for decades.

David Lambert Griffith University, Queensland, Australia. Craig Millar University of Auckland, New Zealand. Eske Willerslev University of Cambridge, UK. d.lambert@griffith.edu.au

\section{Past US floods give lessons in retreat}

The movement of people and infrastructure out of vulnerable areas, a process called managed retreat, is gaining recognition as a potential adaptation strategy to climate change and natural hazards (see also M. Hino et al. Nature Clim. Change 7, 364-370; 2017). Although research into the effectiveness of this process is scarce, the long history of retreat in US flood management offers some useful lessons.

In 1993, the US Congress amended the Robert T. Stafford Disaster Relief and Emergency Assistance Act to authorize the Federal Emergency Management Agency to purchase vulnerable properties and encourage retreat. Since then, the agency has purchased roughly 38,500 properties in 44 states. Acquired buildings were destroyed to create open public spaces.

Retreat in even small numbers can have a large effect. After Hurricane Sandy in 2012, New York state acquired just 300 out of 10,000 damaged homes, but removed two entire neighbourhoods. Whole towns have relocated too, including Pattonsburg in Missouri, Valmeyer in Illinois and Soldiers Grove in Wisconsin.

Such cases can provide guidance on when to retreat, where to relocate and how to coordinate state and federal agencies. Scientists should evaluate past initiatives to identify best practices for the future, when managed retreat may need to be executed on even larger scales.

A. R. Siders Stanford University, California, USA.

siders@stanford.edu

\section{More nuclear power can speed $\mathrm{CO}_{2}$ cuts}

Christiana Figueres and colleagues note that turning around global carbon dioxide emissions by 2020 may not be feasible through renewable energy alone (Nature 546, 593 595 ; 2017). Low-carbon nuclear power will be needed as well.

Historically, energy transitions take decades. When forest destruction in the time of Queen Elizabeth I forced Londoners to move from wood fuel to coal, they resisted fiercely. Many houses lacked chimneys, meat roasted over a coal fire tasted terrible, and preachers condemned the fuel as the Devil's excrement. Petroleum had little application beyond lubrication and lamp-lighting until the commercial introduction of the car in the late 1880 s.

Concerns about accidents and waste disposal are delaying nuclear-power developments. Nuclear accidents have claimed fewer lives than any other energy source (A. Markandya and P. Wilkinson Lancet 370, 979-990; 2007), even including the death toll of the 2011 Fukushima disaster. Effective nuclear-waste disposal is possible: for example, the US Waste Isolation Pilot Plant near Carlsbad, New Mexico, buries waste 700 metres below ground in a 1.8-kilometre-thick bed of salt.

Moreover, nuclear power as an energy source prevented an average of 1.84 million emissions-related deaths in 1971-2009 (P. A. Kharecha and J. E. Hansen Environ. Sci. Technol. 47, 4889-4895; 2013). Richard Rhodes Half Moon Bay, California, USA. richardrhodes1@comcast.net

\section{Ingenious solutions sparked by a crisis}

Researchers have taken to recycling laboratory helium in the face of dwindling supplies resulting from the blockade of Qatar (Nature 547, 16; 2017). Such extreme situations have also prompted other scientists to devise imaginative alternatives in the past.

In the First World War, for example, German naval blockades caused a shortage of acetone and butanol, both essential for munitions. Chaim Weizmann at the University of Manchester, UK (a scientist who later became president of Israel), promptly invented a process for making both chemicals in bulk from starch fermentation using the bacterium Clostridium acetobutylicum.

And a British naval blockade, in turn, propelled German scientists into hijacking another fermentation process to create glycerol, needed to synthesize the explosive trinitroglycerine. They used bisulfite to divert the fermentation of sugars in yeast into glycerol instead of ethanol (go.nature.com/2vkvq7k). Biswa Prasun Chatterji St Xavier's College, Mumbai, India. biswaprasun@gmail.com 